\title{
Conhecimento Especializado do professor que ensina matemática relativo ao tópico de divisão
}

\author{
Kindergarten and Primary teacher's Specialized Knowledge on the topic of division \\ Milena Soldá Policastro ${ }^{1}$ \\ Miguel Ribeiro ${ }^{2}$
}

\begin{abstract}
Resumo
Assumindo que o conhecimento do professor exerce um papel crucial em sua prática e nas aprendizagens dos alunos e por ser a divisão um dos tópicos mais problemáticos para professores e para alunos, focamos nossa atenção no conteúdo do Conhecimento Especializado, revelado em um curso de especialização relativamente a este tópico, por professores que atuam desde a Educação Infantil. O material coletado das interações dos professores, ao discutirem uma tarefa para a formação, foi analisado segundo a lente do Mathematics Teachers' Specialized Knowledge, com intuito de caracterizar o conteúdo do Conhecimento Especializado do professor no tópico de divisão. Dessa análise, emergiram descritores do Conhecimento Especializado do professor de e que ensina matemática relacionado a conceitos, procedimentos, propriedades, fundamentos e sistemas representacionais no âmbito da divisão, contribuindo para que, nos contextos formativos, sejam intencionalmente implementados instrumentos eficazes para desenvolver tal conhecimento.
\end{abstract}

Palavras-chave: MTSK; Divisão; Educação Infantil e Anos Iniciais; Formação de Professores.

\begin{abstract}
Considering teachers' knowledge plays a central role in their practice and on students' learning, and as the division is one of the most problematic topic for teachers' and students', we focus our attention on the content of kindergarten and primary teachers' specialized knowledge who participated of a teacher education program in Brazil, related to such topic. Data concerns teachers' interactions when discussing a task and was analysed according to the Mathematics Teachers' Specialized Knowledge perspective to characterize the content of such a knowledge on division. From the analysis, emerged a set of descriptors of teachers' specialized knowledge related to concepts, procedures, properties, foundations and systems of representation in the scope of division. It contributes to improve the way teachers' training programs are conceptualized, providing elements to intentionally implement effective instruments for the development of such a teacher's knowledge.
\end{abstract}

Keywords: MTSK; Division; Kindergarten and Primary school; Teacher Education.

\section{Introdução}

As especificidades do conhecimento do professor de matemática têm sido foco de

\begin{abstract}
Submetido em: 03/11/2020 - Aceito em: 01/02/2021 - Publicado em: 02/06/2021
${ }^{1}$ Mestre em Ensino de Ciências e Matemática (USP). Doutoranda do Programa de Pós-Graduação Faculdade de Educação (UNICAMP), Campinas, São Paulo, Brasil. E-mail: mitapolicastro@gmail.com. ORCID: https://orcid.org/0000-0003-2437-2557
\end{abstract}

2 Doutor em Didática da Matemática (UHU). Docente do Programa de Pós-Graduação Multiunidades em Ensino de Ciências e Matemática (PECIM), Campinas, São Paulo, Brasil. E-mail:cmribas78@gmail.com. ORCID: https://orcid.org/0000-0003-3505-4431 
DOI: $10.20396 /$ zet.v29i00.8661906

várias pesquisas nas últimas décadas (e.g., Ball, Thames \& Phelps, 2008; Carrillo et al., 2018; Rowland, Huckstep \& Thwaites, 2005). Congressos internacionais de relevância na área da Educação Matemática (por exemplo, $\mathrm{ICME}^{3}, \mathrm{PME}^{4}, \mathrm{CERME}^{5}$ ) têm, a cada ano, discutido mais trabalhos voltados a essa temática. Embora as pesquisas com ênfase no conhecimento do professor apresentem certas divergências relativas a aspectos centrais para a caracterização das especificidades desse conhecimento, há um consenso entre elas sobre o fato de que um amplo e profundo conhecimento do conteúdo a ser ensinado exerce um papel crucial na prática do professor (Dooren, Verschaffel \& Onghena, 2002; Fennema \& Franke, 1992; Ribeiro, 2011a). Paralelamente, outro centro de atenção considerado nas investigações relaciona o conhecimento do professor, nas suas mais variadas dimensões, constatando o impacto que este conhecimento exerce nas aprendizagens discentes (Boyd, Grossman, Lankford, Loeb \& Wyckoff, 2009).

Documentos oficiais de diferentes países, exames internacionais, como é o caso do PISA, e programas educacionais específicos para o desenvolvimento de futuros profissionais com capacidades e habilidades voltadas às áreas de ciências, tecnologia, engenharia e matemática (STEM), atribuem à matemática um papel particularmente relevante. Assim, torna-se essencial ampliar e aprofundar a compreensão acerca das especificidades do conhecimento do Professor de e que Ensina Matemática (PEM), de modo a poder problematizar, por exemplo, aspectos relacionados com a qualidade da formação docente que se tem oferecido, em particular, mas não exclusivamente, no Brasil.

Dentre os tópicos matemáticos mais problemáticos a serem explorados com os alunos, destacam-se aqueles relacionados às quatro operações. São reconhecidas as dificuldades relacionadas a tais tópicos (Fosnot \& Dolk, 2001; Rizvi, 2007), tradicionalmente enfrentadas tanto pelos alunos quanto pelos professores, e, nesse contexto, a divisão é considerada particularmente problemática (Correa, Nunes \& Bryant, 1998; Fischbein, Deri, Nello \& Marino, 1985). Essas dificuldades estão associadas, entre outros aspectos, à priorização do saber fazer o algoritmo, em detrimento do entendimento e da atribuição de significado à operação; ao uso (in)adequado de determinadas verbalizações associadas aos procedimentos (Simon, 1993); ao não estabelecimento das conexões entre a divisão e as demais operações (Young-Loveridge \& Bicknell, 2018); à pouca (ou nenhuma) atenção que se dá nesse contexto aos princípios de contagem e de agrupamento de quantidades em uma unidade unitizing (Behr, Harel, Post \& Lesh, 1994).

A pesquisa relacionada com o ensino e a aprendizagem da divisão tem assumido o foco prioritário de "identificar, descrever e analisar os erros e estratégias de resolução em relação aos conceitos de divisão" (Fávero \& Neves, 2012, p. 36) por parte dos alunos, sem considerar o papel do professor e do seu conhecimento. Em uma revisão sistemática de dez anos de pesquisa dedicada ao ensino e à aprendizagem da divisão e dos racionais, Fávero e

\footnotetext{
${ }^{3}$ International Congress on Mathematics Education

${ }^{4}$ Psychology on Mathematics Education

${ }^{5}$ The Congress of the European Society for Research in Mathematics Education
} 
Neves (2012) apontam uma prática do professor, centrada ou "restrita na exposição de regras, em detrimento do conceito e, consequentemente, voltada à memorização, em detrimento do raciocínio" (p. 60). Esse tipo de abordagem associa-se a uma prática que tem por objetivo último o "saber fazer", e não o entender, ou seja, um tipo de ensino instrumentalizador e não voltado ao estabelecimento de relações (Skemp, 1989).

Assim, para cada um dos tópicos matemáticos e, em particular, para a divisão, é fundamental que se considerem os aspectos que tornam especializado o conhecimento do professor, levando-se em conta não somente o que ele conhece (ou precisa conhecer), mas, essencialmente, a forma como esse conhecimento se estrutura para dar coerência e coesão aos processos de ensino e de aprendizagem. Essa especialização é entendida aqui no sentido do Mathematics Teacher's Specialised Knowledge - MTSK (Carrillo et al., 2018), e está incorporada no domínio tanto do conhecimento do conteúdo quanto do conhecimento pedagógico do conteúdo. Objetivando, assim, ampliar o entendimento relativamente ao conteúdo do conhecimento matemático do professor no âmbito da divisão, aqui perseguimos a seguinte questão: Que elementos caracterizam o conhecimento do tópico de divisão de PEM que participam de um contexto de Formação Continuada?

\section{Perspectivas teóricas no âmbito da divisão}

Dentre as quatro operações, a divisão é considerada a mais complexa e problemática para os alunos (e.g., Bicknell, Young-Loveridge, Lelieved \& Brooker, 2015; Fischbein et al., 1985), o que tem levado a que sua discussão (pelo menos formal) seja deixada por último, assumindo-se uma organização hierárquica do ensino dessas operações. Porém, tal hierarquização, assumindo uma abordagem disjunta, propicia que não se evidenciem as conexões existentes entre as quatro operações (Young-Loveridge \& Bicknell, 2018) e tampouco entre conceitos fundamentais presentes em distintos contextos da matemática escolar, como é o caso das noções de agrupamentos - unitizing - (Behr et al., 1994) e de relações entre parte e todo (Young-Loveridge, 2001).

Quando se trata do ensino das operações, as dificuldades dos alunos podem estar relacionadas, por exemplo, a assumir o algoritmo como ponto de partida (Correa et al., 1998), tendo como foco os procedimentos vistos como regras destituídas de significado (Fávero \& Neves, 2012; Ribeiro, Policastro, Mamoré \& Di Bernardo, 2018). Essa ausência de significação pode estar relacionada com a pouca (ou nenhuma) atenção dada às relações entre os procedimentos e os conceitos subjacentes (Robinson \& LeFevre, 2012), tais como a comparação entre quantidades - dividendo e divisor -, o todo de referência ou os sentidos associados à operação, o que faz com que os alunos não compreendam o que devem fazer e por que o devem fazer em cada momento (Ribeiro et al., 2018).

A compreensão da divisão se sustenta em uma constante comparação entre os elementos envolvidos (dividendo, divisor e quociente), o que vai além da compreensão da distribuição de elementos expressos por números, presentes tradicionalmente em problemas e operações do tipo "arme e efetue" (Lautert, Oliveira \& Correa, 2017). Embora se reconheça a 
importância do trabalho com os algoritmos (Brocardo, Serrazina \& Kraemer, 2003), muito antes deles, é essencial que os alunos entendam os sentidos da operação, dando especial atenção aos papéis dos elementos nela envolvidos (Correa et al., 1998; Squire \& Bryant, 2002) e às relações entre eles (e.g., divisibilidade, multiplicidade e proporcionalidade).

Dentre os sentidos da divisão (Fischbein et al., 1985), assumimos a partilha equitativa e a medida como sendo os que consideramos mais apropriados para discutir com professores e alunos da Educação Infantil e dos Anos Iniciais. Os contextos de partilha equitativa correspondem a situações em que se pretende distribuir (ou repartir) equitativamente uma quantidade de elementos de um conjunto inicial (dividendo) entre determinada quantidade de conjuntos (divisor) - de modo a que, após a partilha equitativa, todos os conjuntos (divisor) contenham a mesma cardinalidade, que corresponde ao quociente. Na divisão no sentido de medida, dada uma quantidade inicial (dividendo), pretende-se identificar quantas vezes (quociente) uma outra quantidade (divisor) é necessária para medir a primeira.

Para entender a divisão, também de forma associada à verbalização usual do algoritmo tradicional $l^{6}$, onde se busca a resposta para a pergunta "que número multiplicado pelo divisor fornece o dividendo?" (Ribeiro et al., 2018), é essencial entender este sentido de medida. Por outro lado, entender a medida demanda compreender alguns dos princípios que fundamentam a atividade de medir, a saber: i) escolha da unidade de medida; ii) partição do todo a ser medido; iii) iteração (repetição) da unidade de medida sobre o todo a ser medido; iv) acumulação de quantidade; v) atribuição de um valor numérico, correspondente à quantificação de vezes que a unidade foi repetida até completar a quantidade relativa ao todo a ser medido (Clements \& Stephan, 2004).

Destacam-se os fatos de que somente a partir de um problema (contexto), em associação com uma determinada verbalização e/ou com uma representação que se efetue, é possível identificar qual dos dois sentidos da divisão é evocado (Fischbein et al., 1985) e perceber que as representações que se podem associar à resolução desses problemas possibilitam atribuir significado a cada um dos conceitos matemáticos envolvidos (Golden \& Shteingold, 2001; Lesser \& Tchoshanov, 2005).

\section{Conhecimento Especializado do Professor}

Diversas investigações na área da Educação Matemática têm buscado caracterizar e ampliar o entendimento dos diferentes domínios do conhecimento do PEM. Dentre as conceitualizações que buscam compreender as especificidades desse conhecimento, assumimos o Mathematics Teachers' Specialised Knowledge ${ }^{7}$ - MTSK - (Carrillo et al., 2018), que considera essas especificidades, no âmbito tanto do Mathematical Knowledge

\footnotetext{
${ }^{6}$ Consideramos aqui o algoritmo tradicional aquele formalmente conhecido por algoritmo euclidiano da divisão.

7 Por ser esta uma conceitualização do conhecimento professor divulgada e reconhecida internacionalmente, mantivemos a nomenclatura em inglês para todos os termos do modelo, pois sua tradução poderia desvirtuar o entendimento dos conteúdos de cada um dos subdomínios que compõem o modelo que a representa (Figura 1).
} 
(MK) como do Pedagogical Content Knowledge (PCK).

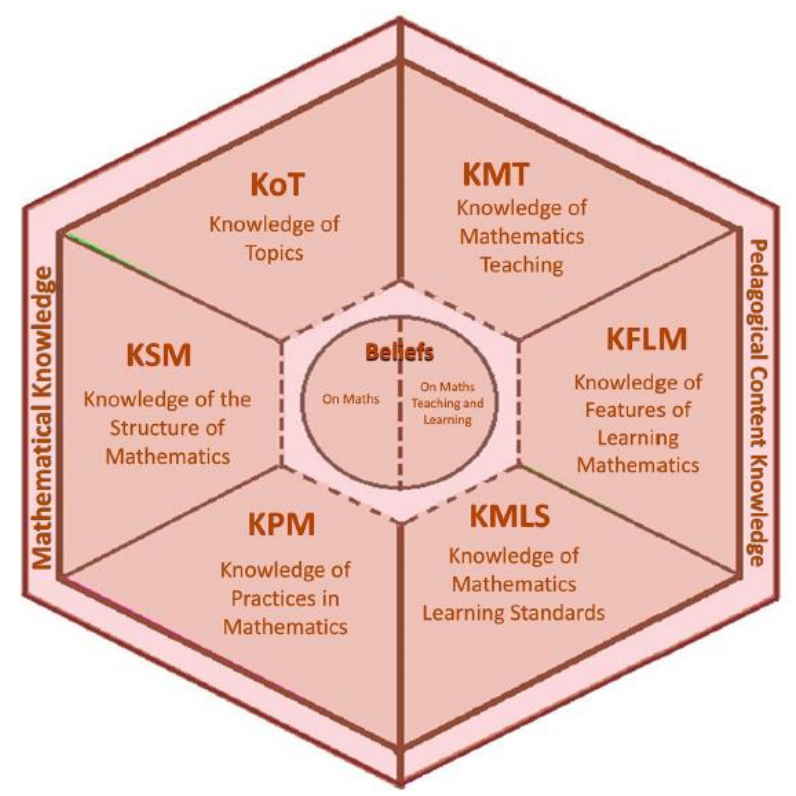

Figura 1 - O modelo MTSK

Fonte: Carrillo et al. (2018, p. 241)

O MK detalha o conhecimento do professor em termos de uma "disciplina científica, dentro de um contexto educacional" (Carrillo et al., 2018, p. 240), enquanto o PCK se refere a esse conhecimento em termos dos processos de ensino e aprendizagem de cada um dos tópicos matemáticos. Importa destacar que o PCK se refere aos conhecimentos do professor em que os tópicos matemáticos são condicionantes para o ensino e a aprendizagem da matemática e, dessa forma, excluímos desse subdomínio os conhecimentos pedagógicos gerais, mesmo em contextos de atividades matemáticas. No modelo, também se incluem as crenças do professor com relação à matemática como ciência e disciplina escolar e com relação ao seu ensino e aprendizagem.

Em cada um dos dois domínios do conhecimento do professor agrupam-se três subdomínios, e, pelo contexto do trabalho que aqui reportamos (ver epígrafe seguinte), discutiremos apenas o subdomínio Knowledge of Topics (KoT) e as respectivas categorias que contemplam o conteúdo do conhecimento do PEM nele incluído.

\section{O Knowledge of Topics (KoT) no âmbito da divisão}

Este subdomínio refere-se, dentre outros aspectos, ao conhecimento do PEM sobre conceitos, fundamentos, procedimentos e à forma como se dão as relações entre eles, quando elas ocorrem dentro de um mesmo tópico. Conhecer como se constituem e se evidenciam essas relações ajuda o professor a trabalhar a matemática de um ponto de vista mais estrutural (Mason, Stephens \& Watson, 2009), oportunizando as aprendizagens (Hiebert \& Grouws, 2007), pois contribui para o desenvolvimento do pensamento estrutural dos alunos em relação à matemática. Refere-se ao conhecimento do professor das diferentes definições matemáticas 
associadas a um mesmo tópico - quando houver mais de uma definição -, incluindo suas distintas formas de apresentação (por meio de linguagem simbólica e/ou verbal); das propriedades e dos fundamentos de um objeto ou ente matemático; dos procedimentos (o que, como, quando e por que se faz de determinada forma) tradicionais ou não convencionais e das implicações dos usos de determinados procedimentos, quando se busca dar sentido a construtos ou conceitos matemáticos; da descrição dos sentidos associados a um determinado conceito ou constructo (fenomenologia) e da associação de contextos capazes de evocar tais sentidos (aplicações); dos distintos sistemas de representações (pictórico, numérico, verbal, gráfico e simbólico) e as relações que se podem estabelecer, dentro de um mesmo tópico, entre esses tipos distintos de representações e certos procedimentos.

No âmbito da divisão, no KoT inclui-se, por exemplo, um conhecimento associado ao significado matemático do que é dividir; aos dois sentidos da divisão; aos diferentes procedimentos associados à operação de divisão, incluindo o algoritmo euclidiano, mas não só; aos distintos tipos de representação para uma divisão e as relações entre elas (por exemplo, pictórica, numérica, verbal), que contribuem para dar significado ao sentido assumido (partilha equitativa ou medida); aos tipos de problemas que podem ser formulados em correspondência com cada um dos sentidos da divisão, entre outros aspectos. Neste subdomínio consideram-se quatro categorias (Carreño, Rojas, Montes \& Flores, 2013), a saber: (i) Definitions, properties and foundations; (ii) Phenomenology and applications; (iii) Procedures; (iv) Registers of representation.

\section{(i) Definitions, properties and foundations}

Inclui o conhecimento do professor relativo aos conceitos mais elementares da matemática, organizados hierárquica e logicamente para dar forma aos conceitos matemáticos mais complexos, ou para caracterizar as definições matemáticas de conceitos. Estão presentes também as propriedades matemáticas relacionadas com cada um dos conceitos, bem como as características estruturais dos construtos e dos conceitos relacionados a um mesmo tópico.

No âmbito da divisão, refere-se ao conhecimento do professor acerca do subconstruto divisor como quantidade de conjuntos entre os quais o dividendo será distribuído - divisão como partilha equitativa -, ou da unidade de medida a ser considerada para medir o todo (dividendo) - divisão como medida. Abrange também o conhecimento de que o significado matemático da divisão se distingue daquele que se refere à decomposição de um número natural em uma adição de parcelas não necessariamente iguais, noção associada ao significado semântico do termo "dividir". Esse conhecimento da não congruência (direta) entre essas duas noções contribui para fundamentar o significado matemático de divisão particularmente no sentido de partilha equitativa.

\section{(ii) Phenomeology and applications}

Aqui se inclui o conhecimento do professor acerca dos fenômenos, dos contextos, das aplicações de um tópico, conceito ou problemas para os quais se busca uma resposta (Gómez 
DOI: $10.20396 /$ zet.v29i00.8661906

\& Cañadas, 2016). No caso da divisão, consideram-se aspectos relacionados com a fenomenologia deste tópico, o conhecimento dos dois sentidos atribuídos à operação partilha equitativa e medida (Fischbein et al., 1985), bem como dos tipos de problemas e contextos (ideias neles contidas) que podem ser formulados de modo a evocar cada um desses sentidos (Downton, 2009), o que corresponde às aplicações desse fenômeno.

\section{(iii) Procedures}

Nesta categoria está contemplado o conhecimento dos diferentes procedimentos que se pode empregar nas situações ou contextos em que determinado conceito está em jogo. Envolve, portanto, o conhecimento que tem o professor de cada um dos passos a serem seguidos; dos diferentes processos que pode empregar com o mesmo objetivo matemático - o que, como, quando e por que se faz; e das características dos resultados obtidos, sempre que se empregam tipos específicos de procedimentos. No tópico da divisão compõe esta categoria o conhecimento do professor sobre as distintas formas de proceder para resolver uma operação de divisão (Bisanz \& LeFevre, 1992), tais como efetuar a divisão por adições ou subtrações sucessivas e por decomposições e/ou agrupamentos; e processos (raciocínios e passos) associados às etapas do algoritmo euclidiano (ou qualquer outro).

\section{(iv) Registers of representation}

Considera-se aqui o conhecimento do professor acerca dos distintos sistemas representacionais (e.g., verbal, simbólico, pictórico, gráfico) que contribuem para dar significado aos conceitos e/ou aos fundamentos de determinados construtos, e também das relações entre as distintas formas de representar um conceito ou construto, de modo a potenciar uma navegação frutífera (Ribeiro, 2011b) entre esses sistemas. É este conhecimento do professor que lhe permite estabelecer uma correspondência entre um objeto matemático (e.g., conceito, construto, fenômeno) e uma imagem conceitual adequada (Golden \& Shteingold, 2001; Timmerman, 2014).

No caso da divisão, importa ainda conhecer a relação e a adequação de um determinado tipo de representação (pictórico, verbal, numérico) com cada um dos sentidos da divisão. Alguns tipos de representação assumem um papel central na atribuição de significado à divisão como partilha equitativa ou como medida e, em especial, a determinados procedimentos associados ao cálculo da operação. E é essencial que o professor conheça essas múltiplas representações e sua correspondência matemática com o sentido evocado, a qual inclui, necessariamente, a verbalização adequada, associada a cada um dos sentidos e significados matemáticos dos construtos (Ainsworth, Bibby, \& Wood, 2002; Golden \& Shteingold, 2001; Lesser \& Tchoshanov, 2005).

Assim, por exemplo, uma verbalização do tipo "quantas vezes o três cabe em seis" não se relaciona adequadamente ao sentido de partilha equitativa, como é usualmente entendido, mas encontra-se associada à noção de comparação de quantidades e posterior quantificação - que corresponde ao sentido de medida. Portanto, ao empregar determinada 
DOI: $10.20396 /$ zet.v29i00.8661906

verbalização, o professor deverá estar consciente (conhecer com correspondência) do sentido da operação que se evoca e dos tipos de raciocínios ali implicados.

\section{Contexto e Método}

Para este trabalho fazemos uso de informações coletadas em um Programa de Formação Continuada (PFC) ${ }^{8}$ com duração de dois anos, composto por oito módulos, com objetivo de desenvolver as especificidades do conhecimento dos participantes em diferentes tópicos matemáticos. Aqui consideramos as informações de uma sessão formativa, de oito horas, em que foi discutida uma tarefa para a formação (Ribeiro, Almeida \& Mellone, 2019) sobre a divisão. Participavam da formação 13 professores, mas apenas 9 estavam presentes no encontro - 1 atuante na Educação Infantil; 7 atuantes nos Anos Iniciais e 1 atuante nos Anos Finais. Para identificá-los, foi atribuído um número a cada um deles ${ }^{9}$ e, portanto, P1 e P2 correspondem a dois professores distintos, mas sem qualquer hierarquia entre eles.

Toda a sessão foi gravada em áudio e vídeo, e as produções das tarefas dos professores foram digitalizadas. Tipicamente os professores resolviam as tarefas em grupo e posteriormente ocorria uma discussão em grande grupo. No encontro analisado, cada grupo tinha três professores ${ }^{10}$ : Grupo 1 - (P14) Anos Finais e (P11 e P19) Anos Iniciais; Grupo 2 três professores dos Anos Iniciais (P3, P4, P8); e Grupo 3 - um professor da Educação Infantil (P18) e dois dos Anos Iniciais (P20 e P2).

Na tarefa para a formação (Ribeiro et al., no prelo) consideraram-se duas partes: Parte I, com foco no Conhecimento Especializado do professor sobre os sentidos, os algoritmos e as representações associadas, no tópico de divisão; e Parte II, com foco no Conhecimento Interpretativo (Jakobsen, Ribeiro \& Mellone, 2014) do professor. Neste trabalho, discutiremos a Parte I da tarefa, cuja implementação ocorreu em duas etapas: resolução em trios, em 3 horas e meia; e discussão plenária, em 1 hora e 45 minutos.

A primeira parte da tarefa continha sete questões e, pelo foco aqui assumido, apresentaremos apenas duas delas. A primeira questão (Cf. Figura 2) objetivava aceder ao conhecimento do professor acerca do conceito matemático de divisão e, em particular, dos dois sentidos atribuídos a essa operação.

\section{PARTE I}

1. O que é dividir? Responda por você mesmo, enquanto professor(a) que ensina matemática e sem considerar um contexto escolar.

\footnotetext{
${ }^{8}$ Curso de Especialização em Matemática oferecido pela Universidade Estadual de Campinas - Unicamp - na modalidade presencial, totalizando 380 horas.

${ }^{9}$ A numeração associada aos pseudônimos dos professores P1, P2, P3, P4, ... tem um caráter de organização da ordem de suas falas (momentos em que se manifestam) durante as diversas sessões de formação que compõem o conjunto de informações da pesquisa maior à qual o recorte para este trabalho se vincula.

${ }^{10}$ Por não ser relevante para as discussões, optamos por não distinguir o gênero de cada um dos participantes e, assim, nos referimos a todos como "professor".
} 
DOI: $10.20396 /$ zet.v29i00.8661906

Figura 2 - Primeira questão da tarefa apresentada aos professores

Fonte: autores (2018)

Partindo da expressão " $6 \div 3$ ", a quarta questão era composta por nove subquestões referentes $\mathrm{a}^{11}$ : (a) procedimentos possíveis para resolução da operação; (b) etapa escolar mais adequada para iniciar a exploração das ideias de divisão; (c) tarefa considerada mais apropriada para introduzir a divisão a alunos do $3 .^{\circ}$ ano dos Anos Iniciais; (d) forma de discutir (tipos e focos de tarefas) a divisão com alunos de 5 anos; (e) tipos distintos de problemas envolvendo a operação; (f) resolução de problemas envolvendo a operação, utilizando tipos distintos de representações e estabelecendo relações entre elas; (g) tipos de resoluções e estratégias de alunos do $2 .^{\circ}$ ano para resolução de problemas envolvendo a operação. Com essas subquestões, objetivava-se aceder ao conhecimento dos professores e desenvolvê-lo acerca dos distintos sentidos da operação de divisão; dos tipos de tarefas, de procedimentos, de representações; e das relações existentes entre cada uma, mais adequadas para se discutir a divisão com alunos de etapas escolares distintas.

As informações coletadas foram organizadas e analisadas considerando suas especificidades (Ribeiro, Carrillo \& Monteiro, 2012). As gravações em áudio foram transcritas e complementadas com as informações provenientes do vídeo - em termos das ações dos participantes, tanto no trabalho em cada um dos grupos como na plenária. Nessas transcrições, cada linha foi indicada por uma numeração do tipo (i.j), em que "i" se relaciona ao subgrupo (1, 2 ou 3) e "j", à linha da transcrição. No caso da discussão plenária, as linhas foram indicadas por (PLj), em que “j”” indica a numeração da linha. Todas as ações e gestos produzidos pelos participantes foram devidamente indicados em negrito em uma linha das transcrições. Além disso, os comentários de cada professor estão associados a seus pseudônimos, indicados por PN, em que "N" corresponde à numeração atribuída a cada um, e os comentários da formadora, que é também a primeira autora deste trabalho, estão indicados por F1. De fato, no PFC, os dois autores deste trabalho atuaram como formadores em diferentes momentos do programa, tendo sido responsáveis por elaborar e implementar as tarefas de formação, dinamizando os encontros com os professores.

Após esta etapa de tratamento das informações, foi analisado o material, composto das transcrições das discussões em subgrupo e plenária e das produções escritas.

Quadro 1 - Exemplo da organização das informações com análise associada

\section{Comentários e registros dos professores}

\footnotetext{
${ }^{11}$ Por falta de espaço não colocamos a questão completa, mas referimos os focos principais associados a cada uma das alíneas incluídas na questão.
} 
DOI: $10.20396 /$ zet.v29i00.8661906

\begin{tabular}{|c|c|}
\hline & $\begin{array}{l}\text { 3.16 P18: "O que é dividir?". É dar um pouquinho do que você tem para o outro. } \\
3.17 \text { P20: Para o segundo ano? } \\
3.18 \text { P18: "Professora ele quer dividir isso comigo!". "Dá um pouco do que você tem para ele. } \\
\text { 3.19 Divide com ele!” } \\
\text { 3.20 P20: Dar um pouco do que você tem ao outro. Isso. }\end{array}$ \\
\hline 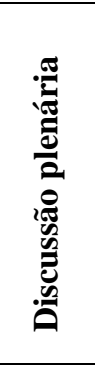 & 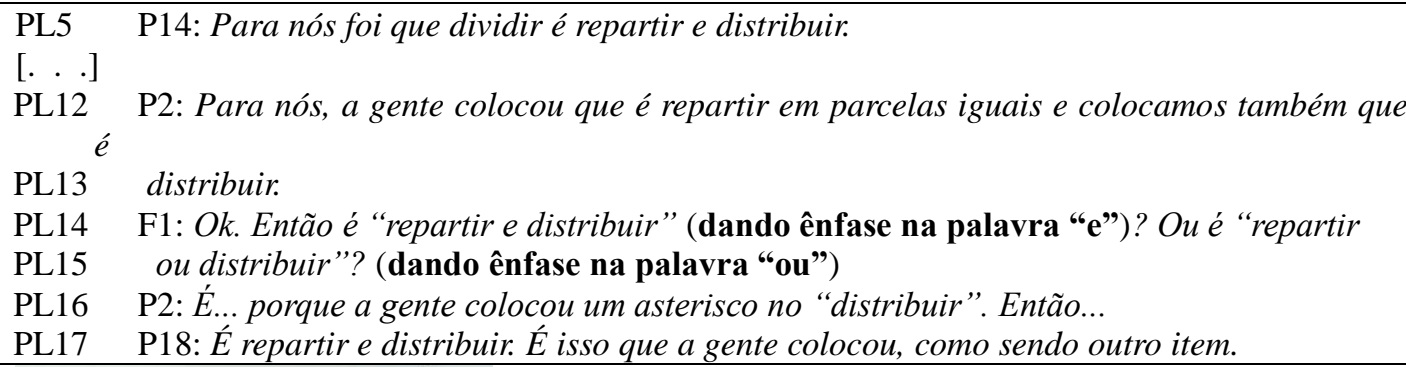 \\
\hline 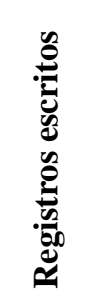 & 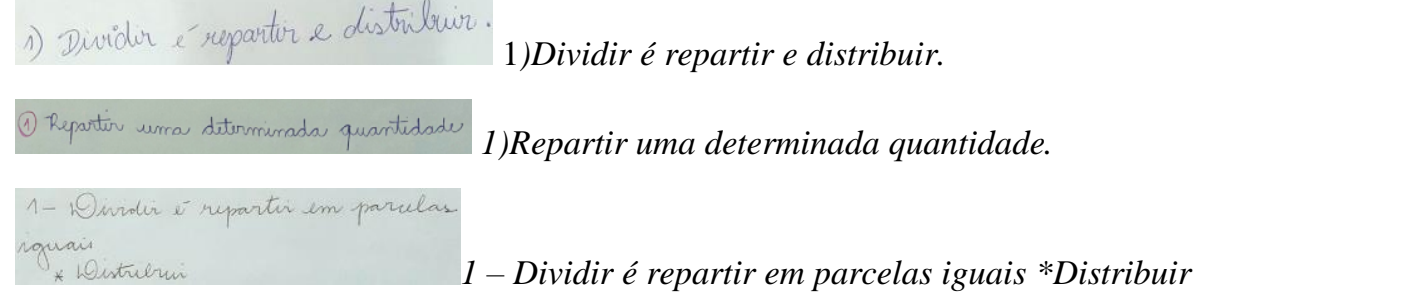 \\
\hline 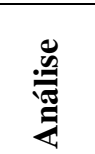 & $\begin{array}{l}\text { Divisão associada ao significado semântico do termo: "repartir", sem que necessariamente as partes } \\
\text { sejam equivalentes. O símbolo matemático da divisão é o que permite associá-la a repartir ou } \\
\text { distribuir em partes equivalentes. Relacionam-se com a ação física de distribuição. }\end{array}$ \\
\hline 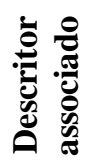 & $\begin{array}{l}\text { KoTd1 - conhecer que é condição necessária para efetuar uma divisão que ocorra a decomposição } \\
\text { do dividendo em partes, e que é condição suficiente que as partes sejam equivalentes. }\end{array}$ \\
\hline
\end{tabular}

Fonte: autores (2020)

Da análise, emergiram elementos característicos das especificidades do conhecimento do PEM em relação ao tópico de divisão e, a partir de um processo cíclico exaustivo, integrando todas as fontes de informação de modo conjunto, foi possível compor um conjunto de descritores do Conhecimento Especializado relacionados às dimensões do KoT.

Quadro 2 - Nomenclatura associada aos descritores relacionados às categorias do KoT

\begin{tabular}{|c|c|c|c|c|c|}
\hline \multirow{2}{*}{ 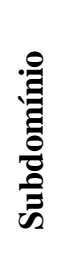 } & \multirow{2}{*}{ 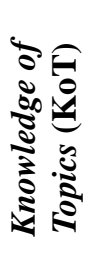 } & $\begin{array}{c}\text { Definitions, } \\
\text { properties and } \\
\text { foundations }(\mathrm{d})\end{array}$ & $\begin{array}{l}\text { Phenomenology } \\
\text { and applications } \\
\text { (ph) }\end{array}$ & Procedures (mp) & $\begin{array}{l}\text { Registers of } \\
\text { representation } \\
\quad(\mathrm{rp})\end{array}$ \\
\hline & & $\operatorname{KoTd} 1 ; \operatorname{KoTd} 2 ; \ldots$ & $\begin{array}{l}\text { KoTph1; KoTph2; } \\
\text { KoTph3, .. }\end{array}$ & $\begin{array}{l}\text { KoTmp1; KoTmp2; } \\
\text { KoTmp3, .. }\end{array}$ & $\begin{array}{c}\text { KoTrp1; KoTrp2; } \\
\text { KoTrp3, .. }\end{array}$ \\
\hline
\end{tabular}

Fonte: autores (2020)

Esses descritores foram denominados segundo as categorias às quais estão associados (Zakaryan \& Ribeiro, 2018), e para cada um se atribuiu uma numeração indicativa da ordem em que aparecem na análise. Na discussão, em alguns casos, sua descrição é apresentada de forma sintética, quando associada a cada uma das evidências identificadas do conhecimento 
revelado pelos PEM e, de forma detalhada, na tabela que apresenta a síntese dos resultados. (Tabela 1, na epígrafe seguinte).

\section{Análise e discussão}

Ao discutirem a primeira questão, dois dos grupos ( 2 e 3 ) revelaram um conhecimento sobre o termo "dividir" que não considera o conceito matemático da operação, pois se ativeram exclusivamente ao sentido semântico do termo:

Quadro 3 - Comentários dos professores relacionados a primeira questão da tarefa

Trecho da discussão no Grupo 2
2.1 P4: Vamos lá... o que é dividir? O que vocês acham?
2.2 P8: Repartir.. não necessariamente em partes iguais.
2.3 Professora escreve o símbolo $\div$
$2.4 \quad$ Agora, se ela tivesse colocado o símbolo, aí já seria em partes iguais.

3.3 P2: Dividir é repartir.

Trecho da discussão no Grupo 3

3.4 P20: É.

3.5 P18: Eu acho também.

3.6 P20: E, para mim, dividir é repartir em partes iguais.

\section{Trecho da discussão plenária}

PL5 P14: Para nós foi que dividir é repartir e distribuir.

[... . $]$

PL13 P2: Para nós, a gente colocou que é repartir em parcelas iguais e colocamos também que é

PL14 distribuir.

PL15 F1: Ok. Então é "repartir e distribuir" (enfatizando a palavra "e")? Ou é "repartir

PL16 ou distribuir"? (enfatizando a palavra "ou")

PL17 P2: É... porque a gente colocou um asterisco no "distribuir".

PL18 P18: É repartir e distribuir. É isso que a gente colocou, como sendo outro item.

Fonte: arquivo dos autores (2018)

Os professores consideram que a divisão deve estar relacionada com o símbolo “ $\div$ ”, para que possa ser entendida como uma operação associada com a obtenção (resultado) de partes equivalentes $(2.3-2.4 ; 3.18-3.20)$. Ao associarem a operação a repartir e/ou distribuir, revelam conhecer que dividir se vincula à ação física de distribuir elementos de um grupo em subgrupos, porém não obrigatoriamente de mesma cardinalidade, em particular quando a divisão é interpretada como partilha equitativa (KoTd1: conhecer a condição para se efetuar uma divisão). Este conhecimento ilustra a necessidade de conhecer o papel do dividendo e do divisor na divisão (Correa et al., 1998) - KoTd2: conhecer os papéis que cada um dos elementos envolvidos na divisão.

No Grupo 3, consideraram que dividir é uma operação que resulta em subgrupos com mesma cardinalidade (KoTmp2: conhecer a natureza do resultado da operação no sentido de partilha equitativa - que dividir é uma operação que resulta em subgrupos com mesma cardinalidade). No entanto, enfatizam a necessidade de distinguir as noções de "repartir" e de "distribuir" (PL13-PL18), que pode estar relacionada com os seus conhecimentos acerca da distinção típica entre os sentidos da divisão envolvendo quantidades discretas (KoTph1: 
conhecer o fenômeno divisão como partilha equitativa) ou quantidades contínuas (KoTph2: conhecer o fenômeno divisão como medida), bem como dos papéis que representam dividendo e divisor numa operação de divisão (KoTd2: conhecer o papel do dividendo e do divisor na divisão), como se identifica no trecho do Quadro 4.

Quadro 4 - Discussão plenária acerca da primeira questão da tarefa

$\begin{array}{ll}\text { PL58 } & \text { P4: Por isso que eu falei, quando você fala em dividir, eles entram no conceito de metade. } \\ \text { PL59 } & \text { P18: Com } 7 \text { anos, por aí, 6, 7, você fala para eles dividirem, eles pegam uma régua! } \\ \text { PL60 } & \text { P20: Milimetricamente, bem dividido. }\end{array}$

Fonte: arquivo dos autores (2018)

Com efeito, embora os professores pareçam considerar haver uma distinção na forma como se pode interpretar a divisão a partir dos seus dois sentidos (Fischbein et al., 1985), no decorrer da discussão evidenciam que essa distinção relaciona-se a um tipo de linguagem verbal e simbólica - que eles consideram mais ou menos adequada para discutir a divisão (KoTrp1: conhecer o papel dos distintos sistemas representacionais na atribuição de significado a conceitos), exclusivamente como partilha equitativa (KoTph1).

Quadro 5 - Discussão plenária com foco na verbalização a ser empregada nos contextos da Divisão

PL118 F1: Vocês disseram que, para o sexto ano, vocês diriam que dividir é repartir em partes iguais.

PL119 Vocês todos concordam com isso?

PL120 Ps: É, para o sexto, é sim...

PL121 Formadora lê um dos registros na lousa.

PL122 F1: Porque espera-se que no sexto ano o algoritmo já tenha sido ensinado.

PL123 Então, a minha pergunta é: o quê do algoritmo me obriga, ou me permite... me provoca dizer que

PL124 são em partes iguais? Por que o algoritmo está associado com a ideia de partes iguais?

PL125 P19: Porque você partiu da operação! E a operação tem o símbolo!

Fonte: arquivo dos autores (2018)

Para esses professores, esse tipo de linguagem se deve empregar especificamente no 6. ${ }^{\circ}$ ano dos Anos Finais, já que, nesta etapa educativa, "espera-se que o algoritmo já tenha sido ensinado" (PL122). De fato, ao associarem o símbolo matemático “ $\div$ ” com um dos sentidos da divisão - KoTrp1 - revelaram conhecer o papel que a linguagem simbólica exerce na atribuição de significado aos construtos matemáticos (Golden \& Shteingold, 2001; Lesser \& Tchoshanov, 2005; Timmerman, 2014). No entanto, não discutem o papel que esse símbolo exerce, quando associado a cada um dos sentidos da divisão (KoTrp2: conhecer o significado do símbolo “־”, i.e., que, no caso da partilha equitativa, ele se relaciona com a distribuição de um todo em subgrupos de cardinalidades equivalentes; e, para o sentido de medida, ele deve ser interpretado como uma relação de comparação entre quantidades medidas).

Ainda com relação ao conhecimento dos distintos sistemas representacionais, durante a discussão do item "a" da questão 4 , na qual se solicitava que determinassem o resultado de $6 \div 3$ e descrevessem os procedimentos utilizados para encontrar a solução, os três grupos forneceram representações que se pautaram no tipo pictórico e numérico (KoTrp1).

Quadro 6 - Registros escritos dos três grupos, relacionados com a quarta questão da tarefa 
DOI: $10.20396 /$ zet.v29i00.8661906

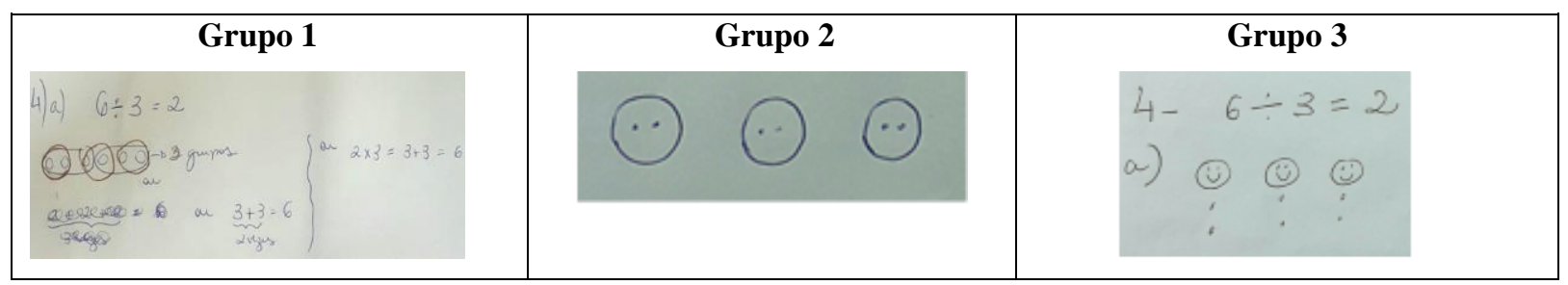

Fonte: arquivo dos autores (2018)

Somente o Grupo 1 buscou estabelecer alguma correspondência entre os dois tipos de registros, ao associar uma adição $(\underbrace{3+3}_{2 \text { vezes }}=6)$ às representações de dois agrupamentos de três

elementos. Esse tipo de registro revela um conhecimento de distintas formas de se navegar frutiferamente entre representações (Ribeiro, 2011b), além de indicar que os professores compreendem ser importante estabelecer relações entre as distintas formas de representação para dar significado aos construtos matemáticos (Ainsworth et al., 2002; Golden \& Shteingold, 2001; Timmerman, 2014) - KoTrp3: conhecer formas de estabelecer relações entre distintas representações. No entanto, essas representações associam-se a considerar a divisão com o sentido de medida (KoTph2), e não como partilha equitativa (KoTph1), mas essa correspondência não é estabelecida de forma consciente pelos professores.

Quadro 7 - Trecho da discussão plenária relacionada com os tipos de representação mais adequados

\begin{tabular}{|ll|}
\hline PL326 & P14: A gente desenhou seis bolinhas e circulou de três em três. \\
PL327 & F1: Então, espera! \\
PL328 & Formadora representa seis círculos na lousa \\
PL329 & \multicolumn{1}{c|}{ Você fez seis bolinhas... } \\
PL330 & P14: É, e circulei de três em três. \\
PL331 & P19: Não! \\
PL332 & P18: Fez dois grupos, então? \\
PL333 & P4: Não, foi de duas em duas! \\
PL334 & P19: Não, de duas em duas. \\
PL335 & P14: De três em três! \\
PL336 & Formadora circula dois grupos de três elementos \\
PL337 & F1: Fez assim? \\
PL338 & Formadora desenha mais seis círculos e circula três grupos de dois elementos \\
Co 9000 \\
PL339 & F1: Ou fez assim? \\
PL340 & P18: Mas era para dividir por três... \\
PL341 & P14: Então, seis bolinhas... \\
PL342 & P19: Era para dividir por três! \\
PL343 & P14: Dividido por três... de três em três. É isso que eu fiz! \\
PL344 & Seis bolinhas, circuladas de três em três. \\
PL345 & P4: Vão dar dois grupos! \\
PL346 & P14: Vão dar quantos grupos? Dois!
\end{tabular}
Fonte: arquivo dos autores (2018)

Durante a plenária evidencia-se algumas dúvidas dos professores relativamente aos tipos de representações pictóricas mais adequadas para evocar os sentidos da divisão, em correspondência com o emprego de uma verbalização específica que dê significado ao sentido evocado, quando a operação for apresentada na forma de uma expressão numérica (6٪3). De fato, a verbalização que P14 emprega (PL326) causa dúvida em P19 (PL 334), um 
dos componentes do Grupo 1, que apresentou dois tipos de registros pictóricos de agrupamento (de três em três e de dois em dois) - cf. Quadro 5 - KoTrp4: conhecer o papel da verbalização. Esse fato pode estar relacionado com a incerteza dos professores sobre o tipo de registro mais adequado para representar $6 \div 3=2$ (KoTrp3).

Com efeito, P4 (PL330-PL333), revela conhecer que a representação pictórica com agrupamentos de dois em dois para compor três grupos é a mais adequada para a resolução da operação (KoTrp5: conhecer os tipos de representação pictórica mais adequada associada aos sentidos da divisão). No entanto, ao mesmo tempo, não estabelece a correspondência de que esse agrupamento é a unidade de medida com a qual o todo está sendo medido (Behr et al., 1994), o que evidencia a necessidade de discutir com esses professores o papel do divisor na operação - KoTd2 -, e também de ampliar seus conhecimentos sobre o sentido de medida da divisão - KoTph2.

De fato, somente com base na representação pictórica (PL338), não é possível afirmar se corresponde a (i) $6 \div 3=2$ ou a (ii) $6 \div 2=3$, pois, caso (i) seja interpretada com o sentido de partilha equitativa, a imagem conceitual (e.g., Golden \& Shteingold, 2001; Timmerman, 2014) que se cria é a de uma distribuição de seis elementos em três subconjuntos com a mesma cardinalidade, dois. Nesse caso, a representação pictórica fornecida ao final da

operação corresponderia a algo como apresentado pelo Grupo 2

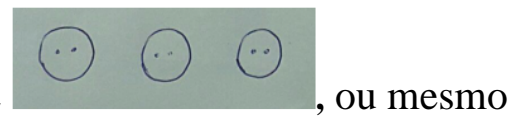

como apresentado pelo Grupo 3

o que evidencia a necessidade de uma adequada verbalização (KoTrp4), com correspondência entre o sentido evocado e a representação pictórica para atribuição de significado a esse sentido (KoTrp5).

Assim, é conteúdo do Conhecimento Especializado do PEM conhecer que a representação 000000 pode estar associada tanto a $6 \div 3=2$ quanto a $6 \div 2=3$ (KoTrp5), e é, portanto, necessário articular mais de uma representação (numérica, por exemplo), incluindo uma adequada verbalização (Simon, 1993), para estabelecer a correspondência entre a expressão e os elementos envolvidos nessa operação (dividendo, divisor e quociente) - KoTd2.

Também a verbalização de P14 (PL330; PL343-344), associada à representação pictórica dos agrupamentos de três em três, evoca o sentido de medida para $6 \div 3=2$ (KoTph2), vinculada à ideia de "quantos grupos de três elementos cabem em um grupo de seis elementos?". No entanto, apesar dessas discussões, os professores não reconhecem explicitamente a divisão para além do sentido de partilha equitativa (KoTph1) ou, pelo menos, não relacionam a verbalização de "quantas vezes cabe" como uma associação inadequada ao sentido de partilha equitativa (KoTrp4). Isso fica claro a partir da análise de uma das subquestões da $4 .^{\text {a }}$ questão da tarefa, em que os professores deveriam propor uma tarefa introdutória sobre a divisão para alunos do $3 .^{\circ}$ ano, associada a discussão dos distintos sentidos da divisão (Fischbein et al., 1985). 
DOI: $10.20396 /$ zet.v29i00.8661906

Quadro 8 - Discussão e registro escrito do Grupo 2, associados à proposta de tarefa introdutória para o 3. ${ }^{\circ}$ ano.

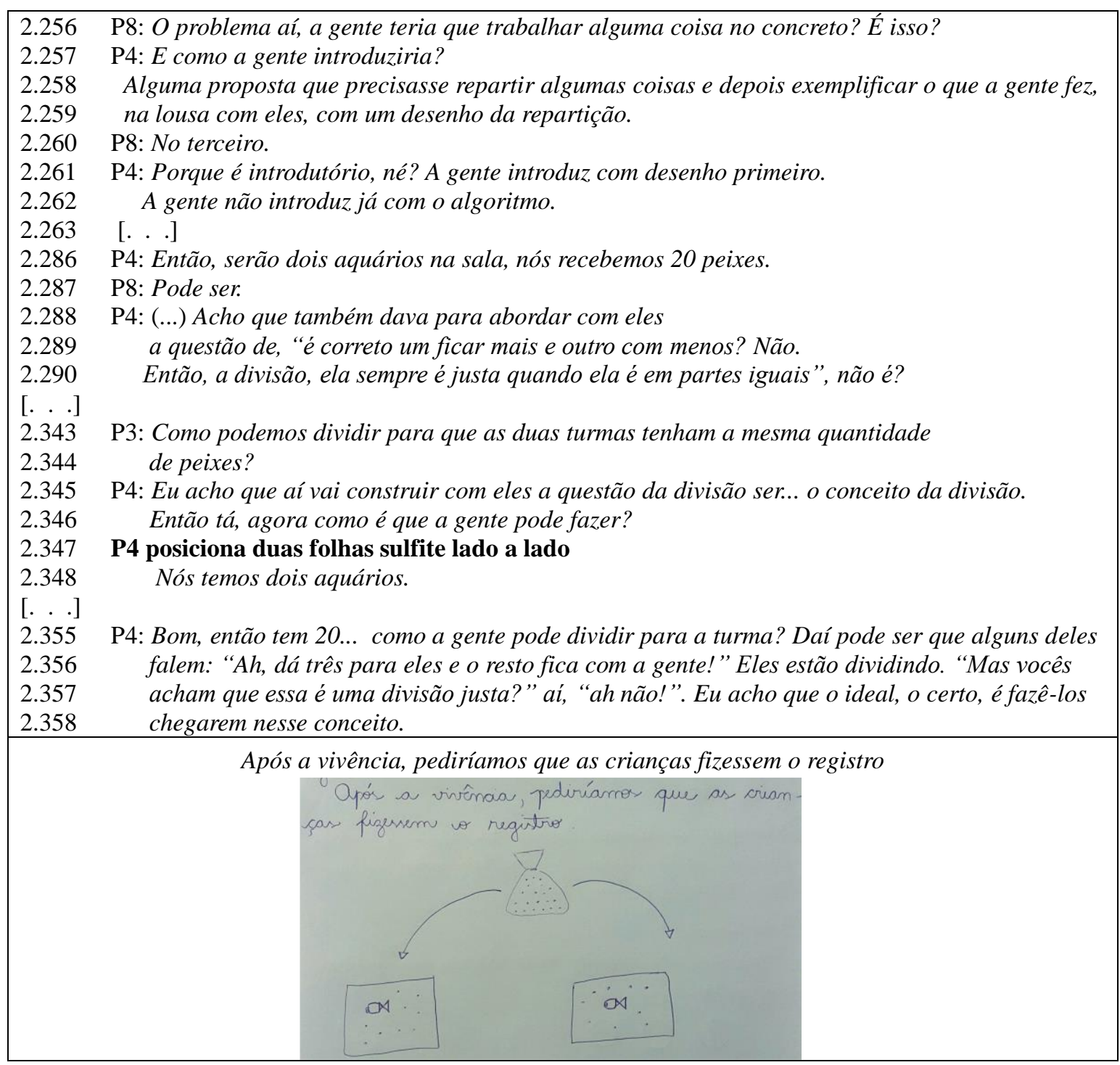

Fonte: arquivo dos autores (2018)

Para os professores, introduzir a operação de divisão com alunos do $3 .^{\circ}$ ano significa, por um lado, desenvolver um trabalho a partir de representações pictóricas $(2.256-2.262)$, o que revela que os professores conhecem o papel desse tipo de representação no processo de atribuição de significado aos conceitos e aos construtos matemáticos - KoTrp2 - (e.g., Ainsworth et al., 2002; Golden \& Shteingold, 2001; Timmerman, 2014). Por outro lado, a noção de introdução da operação de divisão se restringe ao trabalho relacionado estritamente com o sentido de partilha equitativa $(2.286$ - 2.358) - KoTph1 -, deixando à margem a discussão do sentido de medida (Fischbein et al., 1985) - KoTph2. 
Quadro 9 - Registro do Grupo 1, associado à tarefa introdutória para o 3. ${ }^{\circ}$ ano

\begin{abstract}
Seria possível a divisão como partilha equitativa trabalhando com material concreto. Inicialmente distribuiríamos para as crianças quantidades diferentes de tampinhas, de modo que as quantidades fossem visivelmente diferentes. E questionaríamos se a divisão foi justa. Diante da negativa proporíamos como resolver isto de uma forma justa, mediando as respostas para se chegar à conclusão de que a maneira mais justa seria dividir em partes iguais.
\end{abstract}

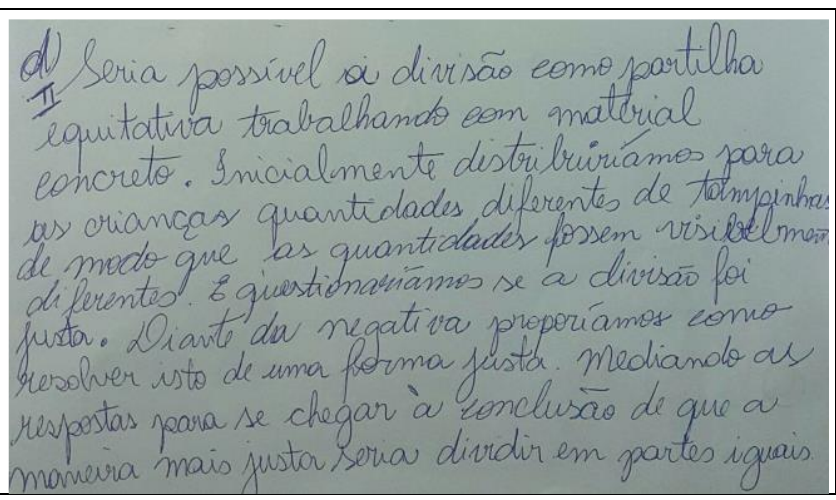

Fonte: arquivo dos autores (2018)

Todos os grupos reconhecem a importância da criação de contextos (problemas) para introduzir a noção de divisão (Downton, 2009) - KoTph3: conhecer os tipos de problemas para evocar os sentidos da divisão. No entanto, apenas o Grupo 2 formulou problemas com dois contextos matemáticos que evocavam os distintos sentidos da divisão (KoTph3) objetivo da subquestão 4 (e).

Quadro 9-Registro escrito com os problemas distintos elaborados pelo Grupo 2

e) 1) Uma caixa contém 6 bombons para serem divididos igualmente para 3 crianças. Quantos bombons cada caixa receberá?

2) Uma caixa contém 6 bombons para serem divididos igualmente. Quantos Cada criança receberá 2 bombons. Quantas crianças receberão bombons?

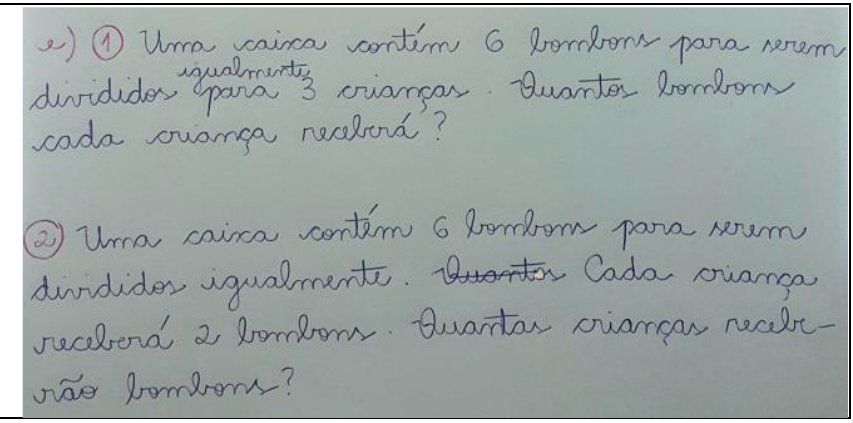

Fonte: arquivo dos autores (2018)

Embora tenham apresentado um contexto evocando cada um dos sentidos da divisão, o segundo problema proposto (Quadro 9), que evoca o sentido de medida, não tem correspondência com a expressão do enunciado $6 \div 3=2$, mas sim com $6 \div 2=3$. A necessidade dessa correspondência forma parte do Conhecimento Especializado do PEM relativo ao papel do dividendo e do divisor na divisão (Correa et al., 1998; Squire \& Bryant, 2002), quando a operação é interpretada a partir de cada um de seus dois sentidos - KoTd2 -, e também sobre a natureza do resultado da divisão no sentido de medida (KoTmp3: conhecer a natureza do resultado da divisão como medida).

Durante a discussão da tarefa, ficou evidente a necessidade de aprofundar a distinção entre os dois sentidos da divisão - em particular dos tipos de contextos que evocam cada um dos sentidos (KoTph3), o que se relaciona também com o fato de o emprego de determinada verbalização, particularmente no algoritmo tradicional, não se adequar ao sentido de partilha 
equitativa (KoTrp4).

Quadro 10 - Trecho da discussão em que se discute o sentido de medida da divisão

\begin{tabular}{|ll|}
\hline PL436 & F1: [... ] eu quero a frase que a P20 diz quando resolve esse algoritmo \\
PL437 & Quantas vezes o três está dentro do seis? \\
PL438 & P20: Está dentro do seis... \\
PL439 & F1: Então, eu volto a perguntar: O que é dividir? \\
PL440 & P14: Ver quantas vezes uma coisa... \\
PL441 & P20: Repartir. \\
PL442 & P2: Repartir. \\
PL443 & F1: Espera um pouco! Se é repartir, aonde está a ideia de repartir com esta frase? \\
PL444 & Quantas vezes o três está dentro do seis? \\
PL445 & P8: Nenhum lugar! \\
PL446 & P2: Nossa! \\
PL447 & P19: Nossa! \\
PL448 & F1: Porque a ideia de repartir, é a ideia de eu... \\
PL449 & Formadora simula distribuir quantidades para cada um todos participantes. \\
PL450 & P2: Distribuir!
\end{tabular}
Fonte: autores (2018)

Para discutir o conhecimento dos professores sobre o sentido de medida associado à divisão (KoTph2), foi necessário a formadora (PL473) tomar como ponto de partida a noção de comparação de quantidades (Clements \& Stephan, 2004) e empregar determinada verbalização (Simon, 1993) associada a uma imagem de distribuição de quantidades (Ainsworth et al., 2002; Golden \& Shteingold, 2001) - KoTrp3. Essa discussão vincula-se ao conhecimento associado ao tipo de contexto (ideia nele contida) que se pode evocar para dar significado ao fenômeno divisão (KoTph3).

Todos os professores revelaram conhecer mais de uma forma de proceder para resolver uma operação (Bisanz \& LeFevre, 1992). Exemplo disso é a discussão ocorrida no Grupo 2 relativamente ao item a) da quarta questão relacionada com a expressão $6 \div 3$ (Determine o resultado dessa operação e descreva os procedimentos e passos realizados para encontrar a resposta):

Quadro 11 - Trecho da discussão no Grupo 2 relacionada ao item a) da questão 4

[2.185] F1: De todo modo, e se fosse qualquer outro valor, se fossem quaisquer outros

[2.186] números que vocês imaginam ali, sei lá, 36 dividido por 3. Como vocês fariam

[2.187] P4: Com o algoritmo!

[2.188] F1: O algoritmo?

[2.189] P3: É!

[2.190] P4: Faria três dividido por três, um.

[2.191] F1: Por que é que o...

[2.192] P4: E seis dividido por três, dois.

[2.193] P8: Eu acho que eu ia pegar 30 primeiro e dividir por três. Depois pegava seis e dividia [2.194] portrês.

[2.195] F1: Tudo bem. Descreve o que...? Que imagem você forma na cabeça quando

[2.196] vai fazer seis dividido por três?

[2.197] P4: Eu formo três... três partes com... quero dizer, duas partes com três.

[2.198] P8: Duas!

[2.199] P4: Não! Três partes com dois (elementos) em cada uma.

[. . .]

[2.209] P8: É, mas eu acho que é isso mesmo que a gente pensa. Você acaba somando $2+2+2$. 
DOI: $10.20396 /$ zet.v29i00.8661906

[2.210] E, se a gente fosse pensar no cálculo mental com o que ela falou, 36, a gente podia [2.211] pegar primeiro as dezenas...depois as unidades...

Fonte: autores (2018)

Para refinar as discussões, foi necessário sugerir uma reflexão sobre a divisão, envolvendo quantidades maiores, pois, para os professores, a operação $6 \div 3$ "já é uma resposta automática" (produção escrita na folha de respostas). Além disso, revelam um conhecimento (KoTmp1: conhecer distintas estratégias de resolução de uma divisão) associado a reconhecer como possibilidade de resolução da operação os procedimentos associados ao algoritmo euclidiano (2.187-2.192); a decomposição do dividendo em parcelas correspondentes a dezenas e unidades (2.193-2.194; 2.210-2.211); os agrupamentos (2.1972.199); e as adições sucessivas (2.209-2.211).

Em forma de síntese dos resultados obtidos, que se focam nas especificidades do KoT mobilizado (e revelado) por PEM no âmbito da divisão em um PFC, apresentamos as categorias e os descritores do conhecimento obtidos.

Tabela 1 - Categorias e descritores relacionados ao subdomínio Knowledge of Topics no tópico de divisão

Categorias

Definitions, properties and foundations (KoTd)

Phenomenology and applications (KoTph)

\section{Descritores}

KoTd1: conhecer que é condição necessária para efetuar uma divisão que ocorra a decomposição do dividendo em partes, e que é condição suficiente que as partes sejam equivalentes.

KoTd2: conhecer o papel do dividendo e do divisor na divisão: na partilha, dividendo corresponde ao todo a ser distribuído e divisor corresponde ao número de subgrupos entre os quais o todo será distribuído; na medida, dividendo corresponde ao todo a ser medido; e divisor, à unidade de medida.

KoTph1: conhecer o fenômeno divisão a partir de sua interpretação como partilha equitativa.

KoTph2: conhecer o fenômeno divisão a partir de sua interpretação como medida.

KoTph3: conhecer os tipos de problemas e contextos (ideias neles contidas) que contribuem para evocar cada um dos sentidos da divisão, i.e., no sentido de partilha, a ideia de distribuição de elementos de um conjunto em subconjuntos; no sentido de medida, a ideia de comparação entre quantidades de mesma grandeza ("quantas vezes uma quantidade cabe dentro da outra?").

KoTmp1: conhecer distintas estratégias de resolução de uma divisão: uma divisão pode ser resolvida pelo algoritmo euclidiano; por decomposição do dividendo em parcelas correspondentes a dezenas e unidades; por agrupamento; e por adições sucessivas.

Procedures $\quad$ KoTmp2: conhecer a natureza do resultado da operação no sentido e partilha (KoTmp) equitativa: o valor numérico obtido - quociente - corresponde à cardinalidade de cada um dos conjuntos entre os quais o todo foi distribuído.

KoTmp3: conhecer a natureza do resultado quando a divisão é entendida como medida: o valor numérico obtido (quociente) corresponde à quantidade de vezes que a unidade de referência coube no todo (agrupar o todo em partes de mesma magnitude). 
KoTrp1: conhecer o papel dos distintos sistemas representacionais na atribuição de significado a conceitos.

KoTrp2: conhecer o significado atribuído ao símbolo " $\div$ ”: relaciona-se com a distribuição de um todo em subgrupos de cardinalidades equivalentes, quando a operação for tomada como partilha equitativa; e o símbolo "†.” está associado ao

Systems of representations

(KoTrp) estabelecimento de uma relação de comparação entre quantidades (medidas).

KoTrp3: conhecer formas de estabelecer relações entre distintas representações para atribuir significado a conceitos, propriedades e/ou procedimentos.

KoTrp4: conhecer o papel do emprego de determinada verbalização para dar significado e/ou corresponder a cada um dos sentidos da divisão.

KoTrp5: conhecer a relação e a adequação dos tipos de representação pictórica, associadas a cada um dos sentidos da divisão: na partilha equitativa, indicando distribuição; na medida, indicando agrupamentos.

\section{Fonte: elaborado pelos autores}

É possível observar uma emergência maior de descritores relacionados às categorias Definitions, properties and foundations e Systems of representations. De fato, o KoT é, dentre os subdomínios que compõem a conceitualização do MTSK, aquele que mais se relaciona com o Conhecimento Especializado do PEM associado ao saber fazer - que se considera conhecimento do nível dos alunos - e com o atribuir significado a conceitos e procedimentos, a partir de fundamentos e propriedades matemáticas. Esta maior emergência justifica-se também pela natureza e pelo foco das questões incluídas na tarefa para a formação, aqui discutidas e pela prática típica dos professores.

\section{Comentários Finais}

Neste trabalho, focamo-nos em explicitar os aspectos que caracterizam o Conhecimento Especializado do PEM relacionado com o tópico de divisão. Esta caracterização objetiva explicitar as especificidades e as particularidades do conhecimento do professor neste tópico e tem também por objetivo representar uma forma de estruturar e organizar os entendimentos que se detêm acerca das especificidades e particularidades do Conhecimento Especializado do PEM, em cada um dos tópicos matemáticos - o que se configura como um avanço na forma de encarar essa especialização (Ball et al., 2008).

Efetuar uma discussão que leve à emergência dessa estruturação, organização e descrição das especificidades, do ponto de vista do professor, uma forma de ele próprio tomar consciência da natureza de uma das dimensões de seu conhecimento profissional, o que lhe permite entender também o papel da pesquisa para a melhoria da formação e da prática. Por outro lado, do ponto de vista da formação de professores, tal estruturação e organização contribuem propiciando novos focos de intencionalidade, por exemplo, na conceitualização de Tarefas Formativas (Ribeiro et al., no prelo) para desenvolver essas especificidades do conhecimento.

Uma atenção especial à natureza e ao conteúdo desse conhecimento e ao foco das formações é essencial sempre e quando se pretende desenvolver as especificidades do conhecimento do professor de e que ensina matemática, pois essas especificidades não se desenvolvem apenas com a prática (Jakobsen et al., 2014). Assim, os resultados deste 
trabalho contribuem para (re)orientar também os focos e os objetivos dos programas de formação (inicial e continuada).

Ao mesmo tempo, os resultados obtidos e os processos analíticos envolvidos, para além de terem potencialidades em termos de pesquisa e de formação, deixam em aberto algumas discussões importantes a considerar - pois essa é também uma forma de contribuir para o avanço do campo - e que se referem, por exemplo, ao que irá ocorrer com estes descritores do conteúdo do conhecimento especializado do PEM, quando confrontados (estressados) com uma análise mais ampla das respostas dos participantes à totalidade da tarefa e com as respostas de outro(s) grupo(s) à mesma tarefa.

Outro aspecto importante a ser considerado relaciona-se com as conexões entre diferentes tópicos que se podem identificar no conhecimento dos participantes (Knowledge of Structures of Mathematics), se mudarmos o foco da lente analítica - em particular conexões no âmbito da divisão e da medida. Tais problemáticas sustentam algumas perguntas de investigações que emergem da análise e da discussão, como sejam: (i) que aspectos caracterizam o conteúdo do Conhecimento Especializado do professor acerca de elementos que compõem as estruturas matemáticas, no âmbito da divisão? (ii) que relações existem (se existirem) entre os descritores de conhecimento associados a cada um dos subdomínios KoT e KSM, no âmbito da divisão? (iii) que conexões entre o tópico de divisão e os tópicos de Medida efetuam os professores, ao discutirem tarefas formativas?

Ademais, estas questões são consideradas também como um dos resultados que nos permitem refletir sobre os rumos que podemos tomar na pesquisa em Educação Matemática com foco no conhecimento, na prática e na formação do professor de e que ensina matemática.

\section{Referências}

Ainsworth, S., Bibby, P., \& Wood, D. (2002). Examining the effects of different multiple representational systems in learning primary mathematics. Journal of the Learning Sciences, 11(1), 25-62.

Ball, D. L., Thames, M. H., \& Phelps, G. (2008). Content Knowledge for Teaching: What makes it special? Journal of Teacher Education, 59(5), 389-407. DOI: https://doi.org/10.1177/0022487108324554

Behr, M. J., Harel, G., Post, T., \& Lesh, R. (1994). Units of quantity: A conceptual basis common to additive and multiplicative intents. In G. Harel \& J. Confrey, The development of multiplicative reasoning in the learning of mathematics (pp. 121-176). Albany, NY: State University of New York Press.

Bicknell, B., Young-Loveridge, J., Lelieved, J., \& Brooker, J. (2015). Using multiplication and division contexts with young children to develop part-whole thinking. Journal Issue, 2, 53-59. DOI: http://dx.doi.org/10.18296/set.0018 
DOI: 10.20396/zet.v29i00.8661906

Bisanz, J., \& LeFevre, J.-A. (1992). Chapter 3 Understanding Elementary Mathematics. In J. I. D. Campbell (Org.), Advances in Psychology (Vol. 91, pp. 113-136). North-Holland. DOI: https://doi.org/10.1016/S0166-4115(08)60885-7

Boyd, D. J., Grossman, P. L., Lankford, H., Loeb, S., \& Wyckoff, J. (2009). Teacher Preparation and Student Achievement. Educational Evaluation and Policy Analysis, 31(4), 416-440. DOI: https://doi.org/10.3102/0162373709353129

Brocardo, J., Serrazina, L., \& Kraemer, J.-M. (2003). Algoritmos e sentido do número. Educação e Matemática, 75(Nov/Dez), 11-15.

Carreño, E., Rojas, N., Montes, M. Á.., \& Flores, P. (2013). Mathematics teacher's specialized knowledge. Reflections based on specific descriptors of knowledge. Proceedings of CERME 8, 2976-2984. Antalya, Turquia: METH.

Carrillo, J., Climent, N., Montes, M., Contreras, L. C., Flores-Medrano, E., Escudero-Ávila, D., ... Muñoz-Catalán, M. C. (2018). The mathematics teacher's specialised knowledge (MTSK) model. Research in Mathematics Education, 20(3), 236-256. DOI: https://doi.org/10.1080/14794802.2018.1479981

Clements, D., \& Stephan, M. (2004). Measurement in pre-K to grade 2 mathematics. In D. Clements, J. Sarama \& A.-M. DiBiase (Orgs.), Engaging Young Children in Mathematics: Standards for Early Childhood Mathematics Education (pp. 299-317). New Jersey: LEA.

Correa, J., Nunes, T., \& Bryant, P. (1998). Young children's understanding of division: The relationship beteween division terms in a noncomputational task. Journal of Educational Psychology, 90(2), 321-329. DOI: https://doi.org/10.1037/0022-0663.90.2.321

Dooren, W. V., Verschaffel, L., \& Onghena, P. (2002). The impact of preservice teachers' content knowledge on their evaluation of students' strategies for solving Arithmetic and Algebra words problems. Journal for Research in Mathematics Education, 33(5), 319351. DOI: https://doi.org/10.2307/4149957

Downton, A. (2009). It Seems to Matters Not Whether it is Partitive or Quotitive Division When Solving One Step Division Problems. In R. Hunter, B. Bicknell \& T. Burgess, Crossing divides: Proceedings of the 32nd annual conference of the Mathematics Education Research Group of Australasia (Vol. 1, pp. 161-168). Palmerston North, NZ: MERGA.

Fávero, M. H., \& Neves, R. S. P. (2012). A divisão e os racionais: Revisão bibliográfica e análise. Zetetiké, 20(37), 33-67. DOI: https://doi.org/10.20396/zet.v20i37.8646635

Fennema, E., \& Franke, M. L. (1992). Teachers' knowledge and its impact. In D. A. Grouws (Ed.), Handbook of research on mathematics teaching and learning: A project of the National Council of Teachers of Mathematics (pp. 147-164). New York: National Council of Teachers of Mathematics.

Fischbein, E., Deri, M., Nello, M. S., \& Marino, M. S. (1985). The role of implicit models in solving verbal problems in multiplication and division. Journal for Reaserch in Mathematics Education, 16(1), 3-17. https://doi.org/10.5951/jresematheduc.16.1.0003

Fosnot, C. T., \& Dolk, M. (2001). Young mathematics at work: Constructing multiplication and division. Portsmouth, NH: Heinemann. 
Golden, G., \& Shteingold, N. (2001). Systems of representation and the development of mathematical concepts. In A. A. Cuoco \& F. R. Curcio, The role of representation in school mathematics (pp. 1-23). Boston, Virginia: NCTM.

Gómez, P., \& Cañadas, M. C. (2016). Dificultades de los profesores de matemáticas en formación en el aprendizaje del análisis fenomenológico. Revista Latinoamericana de Investigación en Matemática Educativa, 19(3), 311-334. DOI: https://doi.org/10.12802/relime.13.1933

Hiebert, J., \& Grouws, D. (2007). The effects of classroom mathematics teaching on students' learning. In F. Lester (Ed.), Handbook of Research on Mathematics Teaching and Learning (pp. 371-404). New York: Information Age Publishing.

Jakobsen, A., Ribeiro, M., \& Mellone, M. (2014). Norwegian prospective teachers' MKT when interpreting pupils' productions on a fraction task. Nordic Studies in Mathematics Education, 19, 135-150.

Lautert, S. L., Oliveira, D. C. A.., \& Correa, J. (2017). Compreensão de crianças sobre relações inversas sem explicitação numérica. Arquivos Brasileiros de Psicologia, 69(1), 73-89.

Lesser, L. M., \& Tchoshanov, M. A. (2005). The effect of representation and representational sequence on students' understanding. In G. M. Lloyd, M. Wilson, J. L. M. Wilkins \& S. L. Behm, Proceedings of the 27th annual meeting of the North American Chapter of the International Group for the Psychology of Mathematics Education (pp. 813-819). Roanoke, Virginia: Virginia Tech.

Mason, J., Stephens, M., \& Watson, A. (2009). Appreciating Mathematical Structure for All. Mathematics Education Research Journal, 21(2), 10-32. DOI: https://doi.org/10.1007/BF03217543

Ribeiro, M. (2011a). A importância do conhecimento do conteúdo matemático na prática letiva de uma professora: Discutindo um modelo de análise. Zetetiké, 19(35), 71-102. DOI: https://doi.org/10.20396/zet.v19i35.8646646

Ribeiro, M. (2011b). Abordagem aos números decimais e suas operações: A importância de uma "eficaz navegação" entre representações. Educação e Pesquisa, 37(2), 407-422.

Ribeiro, M., \& Amaral, R. (2015). Early years' prospective teachers' specialized knowledge on problem posing. Proceedings of 39th Psychology of Mathematics Education Conference, 4, 81-88. Hobart, Australia: Beswick, K., Muir, T. \& Wells, J.

Ribeiro, M., Carrillo, J., \& Monteiro, R. (2012). Cognições e tipo de comunicação do Professor de matemática. Exemplificação de um modelo de análise num episódio dividido. Revista latinoamericana de investigación en matemática educativa, 15(1), 93121.

Ribeiro, M, Almeida, A. R., \& Mellone, M. (2019). Desenvolvendo as especificidades do conhecimento interpretativo do professor e tarefas para a formação. In V. Giraldo, J. Viola, \& H. R. Elias, Problematizações sobre a Formação Matemática na Licenciatura em Matemática [s.1.]. SBEM. No prelo.

Ribeiro, M, Policastro, M., Mamoré, J., \& Di Bernardo, R. (2018). Conhecimento Especializado do professor que ensina Matemática para atribuir sentido à divisão e ao algoritmo. Educação Matemática em Revista - RS, 1(19), 152-167. 
DOI: $10.20396 /$ zet.v29i00.8661906

Rizvi, N. F. (2007). Prospective teachers' knowledge: Concept of division. International Education Journal, 8(2), 377-392.

Robinson, K. M., \& LeFevre, J.-A. (2012). The inverse relation between multiplication and division: Concepts, procedures, and a cognitive framework. Educational Studies in Mathematics, 79(3), 409-428. DOI: https://doi.org/10.1007/s10649-011-9330-5

Rowland, T., Huckstep, P., \& Thwaites, A. (2005). Elementary teachers' mathematics subject knowledge: The knowledge quartet and the case of Naomi. Journal of Mathematics Teacher Education, 8(3), 255-281. DOI: https://doi.org/10.1007/s10857-005-0853-5

Simon, M. A. (1993). Prospective Elementary Teachers' Knowledge of Division. Journal for Research in Mathematics Education, 24(3), 233-254. DOI: https://doi.org/10.5951/jresematheduc.24.3.0233

Skemp, R. R. (1989). Mathematics in the primary school. London: Routledge Falmer.

Squire, S., \& Bryant, P. (2002). From sharing to dividing: Young children's understanding of division. Developemental Science, 5(4), 452-466. DOI: https://doi.org/10.1111/1467$\underline{7687.00240}$

Timmerman, M. A. (2014). Making Connections: Elementary Teachers' Construction of Division Word Problems and Representations. School Science and Mathematics, 114(3), 114-124. DOI: https://doi.org/10.1111/ssm.12059

Young-Loveridge, J., \& Bicknell, B. (2018). Making connections using multiplication and division contexts. In V. Kinnear, T. Muir \& M. Y. Lai (Orgs.), Forging Connections in Early Mathematics Teaching and Learning, Early Mathematics Learning and Development, (pp. 259-272). Brisbane, Autralia: Lyn D. English.

Young-Loveridge, J. M. (2001). Helping children move beyond counting to part-whole strategies. Teachers and Curriculum, 5, 72-78.

Zakaryan, D., \& Ribeiro, M. (2018). Mathematics teachers' specialized knowledge: A secondary teacher's knowledge of rational numbers. Research in Mathematics Education, 21(3), 1-19. DOI: https://doi.org/10.1080/14794802.2018.1525422 